\title{
贝加尔裂谷区地幔过渡带大范围增厚与局部减薄 现象及其动力学意义
}

司少坤 ${ }^{(1)}$, 田小波 ${ }^{(1 *}$, 张洪双 ${ }^{(1)}$, 滕吉文 ${ }^{(1)}$

(1) 中国科学院地质与地球物理研究所, 北京 100029;

(2) 中国科学院研究生院, 北京 100049

* 联系人, E-mail: txb@mail.iggcas.ac.cn

收稿日期: 2011-11-25; 接受日期: 2012-05-20

国家自然科学基金(批准号：40974025, 40721003)、国家自然科学基金创新研究群体科学基金(批准号：41021063)和国家重大专项(编号: 2008ZX05008-006)资助

\begin{abstract}
摘要只加尔裂谷是世界上地震活动最强烈的裂谷带, 其动力学成因机制是地球科学界关 注的热点课题之一。我们利用全球地震台网长期运行台站 TLY 和 ULN 的远震资料, 分别计算 了 $\mathrm{P}$ 波接收函数(1748 条), 并在一定角度范围内分区域叠加, 获得了研究区下方的 $410 \mathrm{~km}$ 和 $660 \mathrm{~km}$ 间断面以及地幔过渡带(MTZ)的厚度. 结果表明在研究区的东南部即蒙古地区地幔过 渡带厚度基本正常 $(250 \mathrm{~km})$; 贝加尔裂谷地区地幔过渡带明显增厚 $(292 \mathrm{~km})$; 裂谷下方存在小 幅度的减薄现象 $(230 \mathrm{~km})$. 综合分析推测, 大范围的 MTZ 增厚, 可能原因是中生代的蒙古华北 板块(Mongolia-North China Block)与西伯利亚高原碰撞, 或者地幔岩浆物质侵入到下地壳, 使 地壳和岩石圈增厚, 致使下地壳产生榴辉岩化, 导致重力不稳发生拆沉作用, 拆离的部分落入 地幔过渡带。拆沉作用诱发软流圈上涌, 且拆离部分携带的水分加剧了上地幔熔融程度, 使地 幔对流速率加快, 有利于裂谷的发育. 我们初步研究结果认为拆沉的破坏作用及其引发一系列 活动对裂谷的发育具有重要的影响，裂谷下方局部 MTZ 减薄所指示的热物质上涌对岩石圈的 破坏可能进一步促进了裂谷的发育.
\end{abstract}

关键词

贝加尔裂谷 地幔过渡带 $\mathrm{P}$ 波接收函数
大陆裂谷是大陆上最为显著的构造地貌类型， 是岩石圈主要的构造类型之一, 对其的研究具有重 要的理论和实践意义 ${ }^{[1]}$. 大陆裂谷有大断层围限的规 模巨大的断陷谷地, 其宽度大多为几十公里, 长度从 几十公里到几千公里不等. 随着大陆裂谷的不断发 育, 当火山活动由碱性变为拉斑玄武岩, 大陆地壳被 拉断, 洋壳出现形成洋中脊裂谷, 大陆裂谷和洋中脊 裂谷联通共同形成了全球裂谷系 ${ }^{[2 \sim 4]}$. 对于裂谷的成
因, Sengor 等 ${ }^{[5]}$ 提出两种类型: (1) 主动裂谷作用, 岩 石圈因软流圈物质上涌而破裂，主动机制预示从隆 起作用 $\rightarrow$ 火山作用 $\rightarrow$ 裂谷作用; (2) 被动裂谷作用, 岩石圈的最初张裂是由于岩石圈板块相互作用产生 差异应力而引起的, 被动机制预示从裂谷作用 $\rightarrow$ 隆 起作用 $\rightarrow$ 火山作用. 贝加尔裂谷带是其中较为复杂 的大陆裂谷, 其动力学机制存在着争议, 另外, 贝加 尔裂谷距离其最近的主动大陆边缘超过 $2000 \mathrm{~km}$, 对

英文引用格式: Si S K, Tian X B, Zhang H S, et al. Prevalent thickening and local thinning of the mantle transition zone beneath the Baikal rift zone and its dynamic implications. Science China: Earth Sciences, 2012, doi: 10.1007/s11430-012-4547-4 
研究陆内裂谷具有重要的意义.

贝加尔裂谷带(Baikal rift zone)位于稳定的西伯 利亚高原和贝加尔-萨彦褶皱带之间，呈北东向绕西 伯利亚地台南缘分布, 地处 $50^{\circ} \sim 58^{\circ} \mathrm{N}, 100^{\circ} \sim 120^{\circ} \mathrm{E}$ 之 间，延绵 $1800 \mathrm{~km}$ 的裂谷带是世界上地震活动最强烈 的大陆裂谷带, 过去的 280 年内在此地区发生了 13 次震级大于 6.5 的强地震 ${ }^{[6]}$. 在大约 30 35 Ma 前, 裂 谷开始沿着西伯利亚板块和阿穆尔微板块之间的古 生代的蒙古-鄂霍次克缝合线发育 ${ }^{[7]}$, 至今水平扩张 总量为 $10 \sim 20 \mathrm{~km}$, 平均每年为 $0.3 \sim 0.6 \mathrm{~mm}^{[8]}$. GPS 测 量发现, 贝加尔裂谷现在正以 10 倍平均速度加速扩 张 ${ }^{[9,10]}$. 与世界上大多数大陆裂谷一样, 贝加尔裂谷

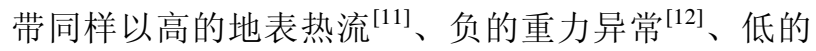
上地幔速度 ${ }^{[13]}$ 为主要特征; 但其也具有特殊性, 在 整个裂谷的发育过程中伴随较少的火山活动, 而且 大部分发生在拉张盆地之内 ${ }^{[14]}$, 造成在本地区具有 较少的火山岩块体, $6000 \mathrm{~km}^{3}$ 的火山岩堆积远远小于 Kenya Rift 地区的 $144000 \mathrm{~km}^{3[15]}$.

前人已经对贝加尔湖地区做了大量的研究, 接 收函数 ${ }^{[16]}$ 研究发现, 在该区有裂谷发育的地区相比于 不发育的地区地壳减薄了 $10 \mathrm{~km}$; 但深部地震探测 ${ }^{[17]}$ 表明研究区内莫霍界面没有明显的起伏变化, 这被 解释为铁镁质的地幔物质通过底侵作用侵入下地壳, 填充了裂谷形成过程中减薄的的地壳; 重力和地震 学 ${ }^{[12,18,19]}$ 研究发现, 贝加尔裂谷处的岩石圈厚度为 40 50 km, 减薄到一地壳厚度, 而其西北方向的西伯 利亚高原岩石圈达 $200 \mathrm{~km}$, 东南方向的蒙古䙒皱带 为 $160 \sim 170 \mathrm{~km}$; 剪切波分裂 ${ }^{[20]}$ 研究表明, 该区存在 两个快波方向 NE 和 NW, 即分别近似平行和垂直于 裂谷的走向: 在裂谷的两侧快波方向为 $\mathrm{NW}$, 而裂谷 中心及附近快波方向为 $\mathrm{NE}$, 快慢波时差大约各为 $1 \mathrm{~s}$. 贝加尔裂谷的动力学演化也是学者们研究的重点, 但其存在着很大争议, 一部分学者 ${ }^{[21 ~ 26]}$ 认为是岩石 圈下面的异常热上地幔导致了贝加尔裂谷的形成发

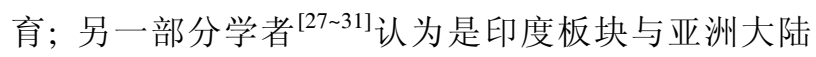
碰撞作用引起喜马拉雅山脉与欧亚大陆之间的板块 发生向东的逃逸, 以及与太平洋板块的俯冲拖曳作 用使已经弱化的岩石圈发生水平拉张的结果; 近来有 一些学者提出是由于多种因素综合作用所形成的 ${ }^{[32 ~ 37]}$, 如 Zhao 等 ${ }^{[36]}$ 认为地幔热物质上涌在贝加尔裂谷的发育 过程中发挥主要作用, 另外, 还受该地区古老的岩石圈 裂隙以及印度-亚洲板块碰撞所形成的远场力控制.
在确定贝加尔裂谷动力演化成因中, 地幔低速 带存在与否、以及低速带所涉及的垂向范围同样存在 着争议。一些学者发现在贝加尔裂谷上地幔存在低 速带 ${ }^{[36,37]}$, 并且认为低速异常成圆柱状从地表延伸 到地幔过渡带, 是下地幔物质上涌形成的 ${ }^{[36,38]}$, 有些 学者进而提出了地幔柱的理论 ${ }^{[39]}$. 而 Petit 等 ${ }^{[40]}$ 没有在 上地幔中找到大范围的、上下贯通的低速带, 认为贝 加尔裂谷的形成发育受深部物质的影响不大.

造成上述争议的原因在于各种方法具有自身的 限制，例如层析成像在深部的分辨率有限，人们对深 部结构的认识缺乏多种地球物理证据的约束. 普遍 认为, $410 \mathrm{~km}$ 和 $660 \mathrm{~km}$ 间断面是地幔物质的相变界 面, 周围温度的改变会影响两个间断面的深度变化. 温度的下降导致 $410 \mathrm{~km}$ 间断面变浅, 而 $660 \mathrm{~km}$ 间断 面变深, 从而导致地幔过渡带增厚, 一般温度下降 $6 \sim 7^{\circ} \mathrm{C}$ 就会造成地幔过渡带增厚 $1 \mathrm{~km}^{[41]}$; 相反, 温度 的升高将导致地幔过渡带减薄. 因此通过对地幔过 渡带厚度变化的研究, 可以从另一个方面对贝加尔 裂谷的动力演化提供约束.

接收函数通过远震波形记录的反褶积运算, 在 径向分量中消除震源时间函数、大圆弧路径传播效应 以及台站的仪器响应, 使得接收函数仅包含反映台 站下方速度结构的转换波及其多次波 ${ }^{[42 ~ 44]} .410 \mathrm{~km}$ 界面、660 km 界面存在明显的速度跃变(P 波 3.6\%和 $5.6 \% ; \mathrm{S}$ 波 $4 \%$ 和 $6 \%{ }^{[45]}$ ), 接收函数方法已被广泛的应 用于地幔过渡带的研究 ${ }^{[46-50]}$. 本文旨在对贝加尔裂 谷地区 $410 \mathrm{~km}$ 界面、 $660 \mathrm{~km}$ 界面以及地幔过渡带厚 度的测量, 对该区域地下深度结构以及裂谷的动力 机制提供新的约束.

\section{1 数据和方法}

在本文中，我们所用到的远震地震数据全部来 自全球地震台网长期运行的台站 TLY 和 ULN, 其分 别位于 $51.68^{\circ} \mathrm{N}, 103.64^{\circ} \mathrm{E}$ 和 $47.87^{\circ} \mathrm{N}, 107.05^{\circ} \mathrm{E}$. TLY 地处贝加尔湖与汤金盆地之间，与贝加尔湖相距 5 $\mathrm{km}$. 在构造上，TLY 位于阿尔泰-萨彦褶皱带与西伯 利亚高原之间. ULN 处于 TLY 的东南方，蒙古块体内 (图 1). 本文选取从 1991 年 3 月至 2010 年 3 月, 震中 距 $30^{\circ} \sim 90^{\circ}$, 震级 $>5.0$ 的具有清晰 $\mathrm{P}$ 波初至和高信噪 比的远震事件. 在带宽为 $0.05 \sim 0.2 \mathrm{~Hz}$ 内采用频率域 反褶积方法计算 $\mathrm{P}$ 波径向接收函数 ${ }^{[51]}$, 从中篮选出 


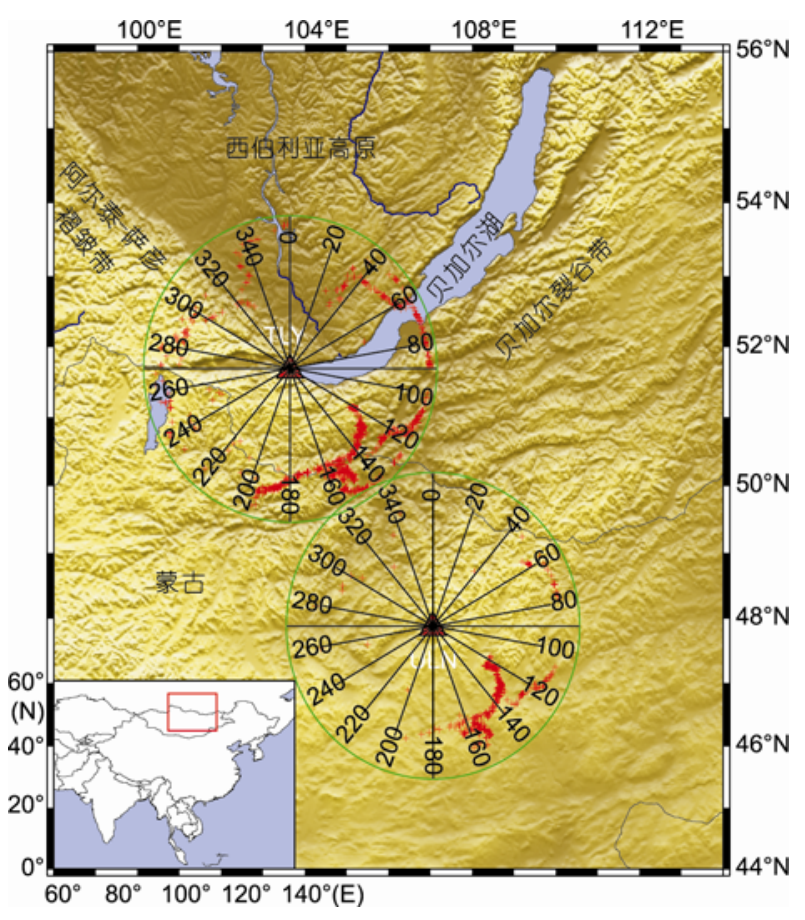

图 1 研究区的构造区域图

红色三角形表示台站, 台站上方的字母为台站代码, 红色十字表示 $540 \mathrm{~km}$ 射线穿透点, 黑线表示划分的 36 个叠加区域, 左下方图中 的红色矩形为研究区所在的位置

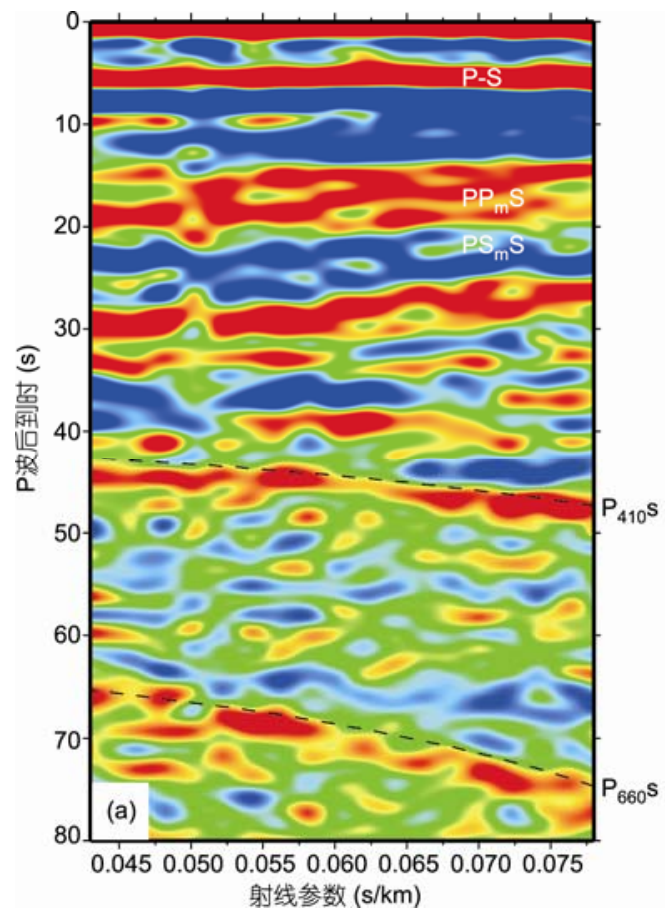

信噪比高的接收函数 1748 条用来进行研究. 其中, 1271 条来自台站 TLY, 477 条属于台站 ULN.

对两个台的接收函数分别进行处理. 对时间域 的数据按照射线参数从 0.04 0.08, 在间隔 0.002 区间 内进行叠加处理(图 2), 从图 2 中可以看出, 莫霍界面 产生的转换波 $\mathrm{P}_{\mathrm{m}} \mathrm{S}$ 和地壳多次波 $\mathrm{PP}_{\mathrm{m}} \mathrm{S}$ 和 $\mathrm{PS}_{\mathrm{m}} \mathrm{S}$ 能够 清晰地得到, 分别出现在直达 $\mathrm{P}$ 波后的 5, 18, 24 s 附 近; $410 \mathrm{~km}$ 和 $660 \mathrm{~km}$ 间断面产生的 $\mathrm{P}_{410} \mathrm{~S}$ 和 $\mathrm{P}_{660} \mathrm{~S}$ 转 换波震相也比较清楚.

我们构建了一个 800 层的平行球形模型, 每层的 厚度为 $1 \mathrm{~km}$, 然后根据 IASP91 地球模型 ${ }^{[45]}$ 、射线参 数、震源和台站的经纬度计算每条接收函数在每一深 度层底界面的转换点位置(经度、纬度)和相对于直达 $\mathrm{P}$ 波的延时, 其中 $540 \mathrm{~km}$ 转换点的位置在图 1 中标出. 根据我们计算出的每层的转换点相对于直达 $\mathrm{P}$ 波的 延时对接收函数进行重采样, 完成接收函数由时间 域到空间域的转换，即由 $r_{i}(t)$ 得到 $r_{i}(h)$.

为增强空间域相关性较强的弱的透射转换震相 $\left(\mathrm{P}_{410} \mathrm{~s}\right.$ 和 $\left.\mathrm{P}_{660} \mathrm{~s}\right)$, 我们采用非线性的相位加权 ${ }^{[52]}(\mathrm{Phase}-$ Weighted Stacks, PWS)方法进行叠加来增强地幔过渡 带顶底界面转换波的能量. PWS 方法具体操作如下:

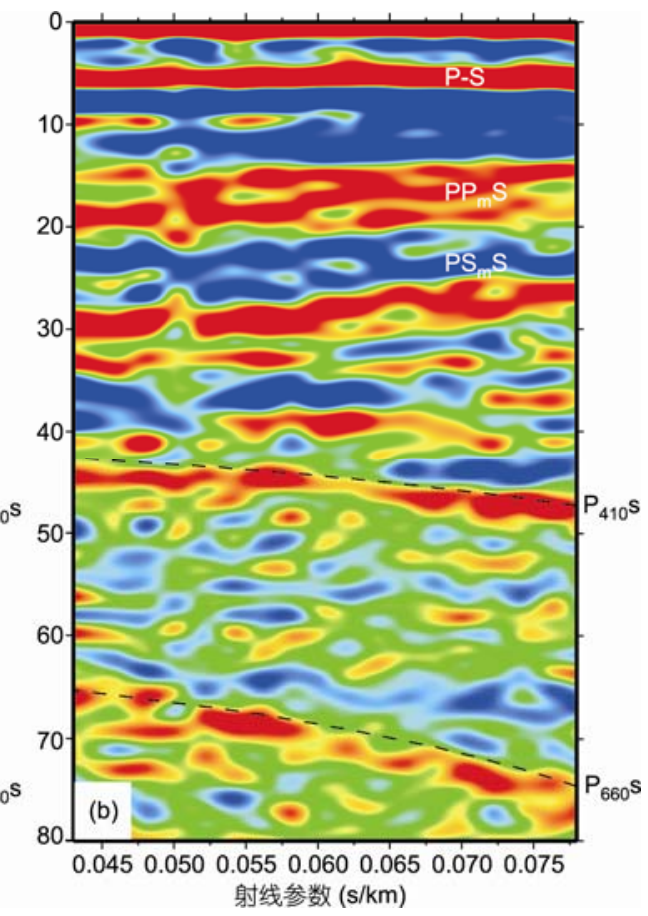

图 2 台站 TLY (a) 和 ULN(b) 的接收函数随射线参数在 0.002 区间内叠加成像图

$\mathrm{P}-\mathrm{S}$ 为莫霍面转换波, $\mathrm{PP}_{\mathrm{m}} \mathrm{S}$ 和 $\mathrm{PS}_{\mathrm{m}} \mathrm{S}$ 表示壳内多次波, $\mathrm{P}_{410} \mathrm{~S}$ 和 $\mathrm{P}_{6600} \mathrm{~S}$ 分别表示 $\mathrm{d} 410$ 和 $\mathrm{d} 660$ 转换波, 两条虚线分别表示根据 IASP91 模型 $\mathrm{d} 410$ 和 $\mathrm{d} 660$ 随射线参数的变化 
用 $r_{i}(h)$ 及其 Hilbert 变换 $H\left(r_{i}(h)\right)$ 构造复数序列 $c_{i}(h)$, 即

$$
c_{i}(h)=r_{i}(h)+i H\left(r_{i}(h)\right),
$$

然后将 $c_{i}(h)$ 写成

$$
c_{i}(h)=A_{i}(h) \mathrm{e}^{j \Psi_{i}(h)},
$$

其中, $A_{i}(h)$ 和 $\Psi_{i}(h)$ 为其振幅和相位. 对落入叠加 区域内的 $n$ 条 $r_{i}(h)$ 曲线所采用的叠加规则为

$$
f(h)=\frac{1}{n} \sum_{i=1}^{n} r_{i}(h)\left|\frac{1}{n} \sum_{i=1}^{n} e^{j \Psi_{i}(h)}\right|^{2} .
$$

如图 3 所示, PWS 方法的效果明显好于线性叠加 结果, 有效地压制了相位一致性较差的噪音, 而突出 相位一致性较好、强度较弱的透射转换震相 $\mathrm{P}_{410} \mathrm{~S}$ 和 $\mathrm{P}_{660} \mathrm{~s}$.

我们采用 bootstrap 抽样算法 ${ }^{[53,54]}$ 来计算间断面 深度的均方差作为误差估计. 对于每一个样本 $X\left(x_{j}, j=1,2, \cdots n\right)$, 其中, $X$ 为在一叠加区间内接 收函数样本, $x_{j}$ 为 $X$ 中第 $j$ 条接收函数, 在下一步 bootstrap 抽样时, 使用随机方法等概率、独立、有放 回的从样本 $X$ 中抽取 $x_{j}$, 使其与原始样本数量相等. 均方差由下面的公式求得:

$$
\sigma=\sqrt{\frac{1}{N-1} \sum_{i=1}^{N}\left(D_{i}-\bar{D}\right)^{2}},
$$

其中, $N$ 为 bootstrap 采样的采样次数, $D_{i}$ 为第 $i$ 次采样
的深度值, $\bar{D}$ 为 $N$ 次采样的深度平均值. 而对于地幔 过渡带厚度值的均方差，我们用以下公式求取：

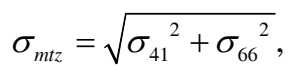

其中, $\sigma_{41}$ 和 $\sigma_{66}$ 分别是 $410 \mathrm{~km}$ 和 $660 \mathrm{~km}$ 间断面的均 方差.

\section{2 结果}

分别以台站 TLY 和 ULN 为圆心, 正北方向为 $0^{\circ}$, 按顺时针方向每隔 $10^{\circ}$ 作为一个叠加中心, 前后 各取 $10^{\circ}$ 作为一个叠加区域, 每个台划分了 36 个叠 加区域(图 1), 根据各台接收函数 $540 \mathrm{~km}$ 转换点所 在的区域进行分区域叠加. 在图 4 和 5 中我们展出 了在叠加区域内接收函数叠加效果较好、叠加震相 清晰的结果.

\section{1 台站 TLY}

从图 1 可以看出, $80 \%$ 的 $540 \mathrm{~km}$ 深度处的透射转 换点位于台站的东半部 $\left(20^{\circ} \sim 200^{\circ}\right.$ 之间 $)$ 一贝加尔裂 谷带所在的位置, 因此, 我们所得的结果东部应比西 部更加可靠, 这一点从数据的均方差上可以得到验 证(图 4). 根据图 4 和表 $1,410 \mathrm{~km}$ 间断面的转换波 $\mathrm{P}_{410} \mathrm{~s}$ 出现在 400-430 km 之间, $660 \mathrm{~km}$ 间断面主要位 于 660 710 km 范围内.
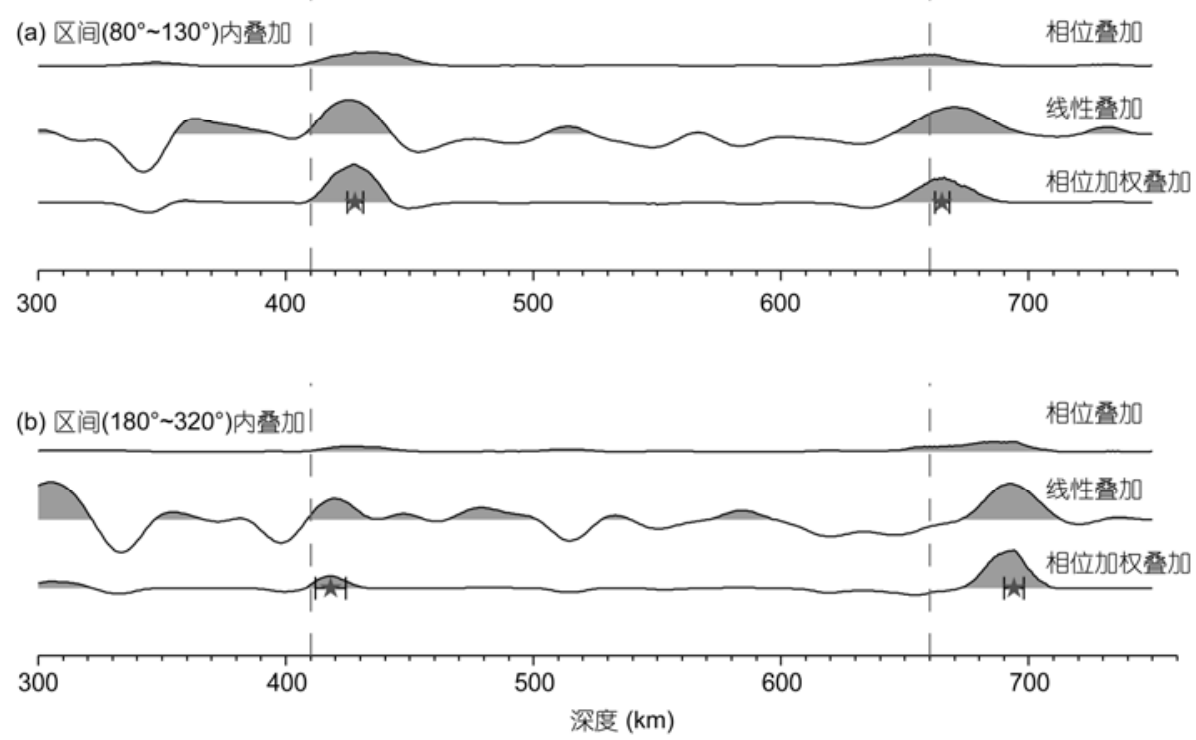

图 3 台站 $\mathrm{TLY}$ 反方位角 $\mathbf{8 0}^{\circ} \sim 130^{\circ}(\mathrm{a})$ 和 $180^{\circ} \sim 320^{\circ}(\mathrm{b})$ 范围内的接收函数用不同方法叠加 五角星代表 $410 \mathrm{~km}$ 和 $660 \mathrm{~km}$ 间断面的深度, 通过 bootstrap 算法计算的均方差作为误差用误差棒标在此处 

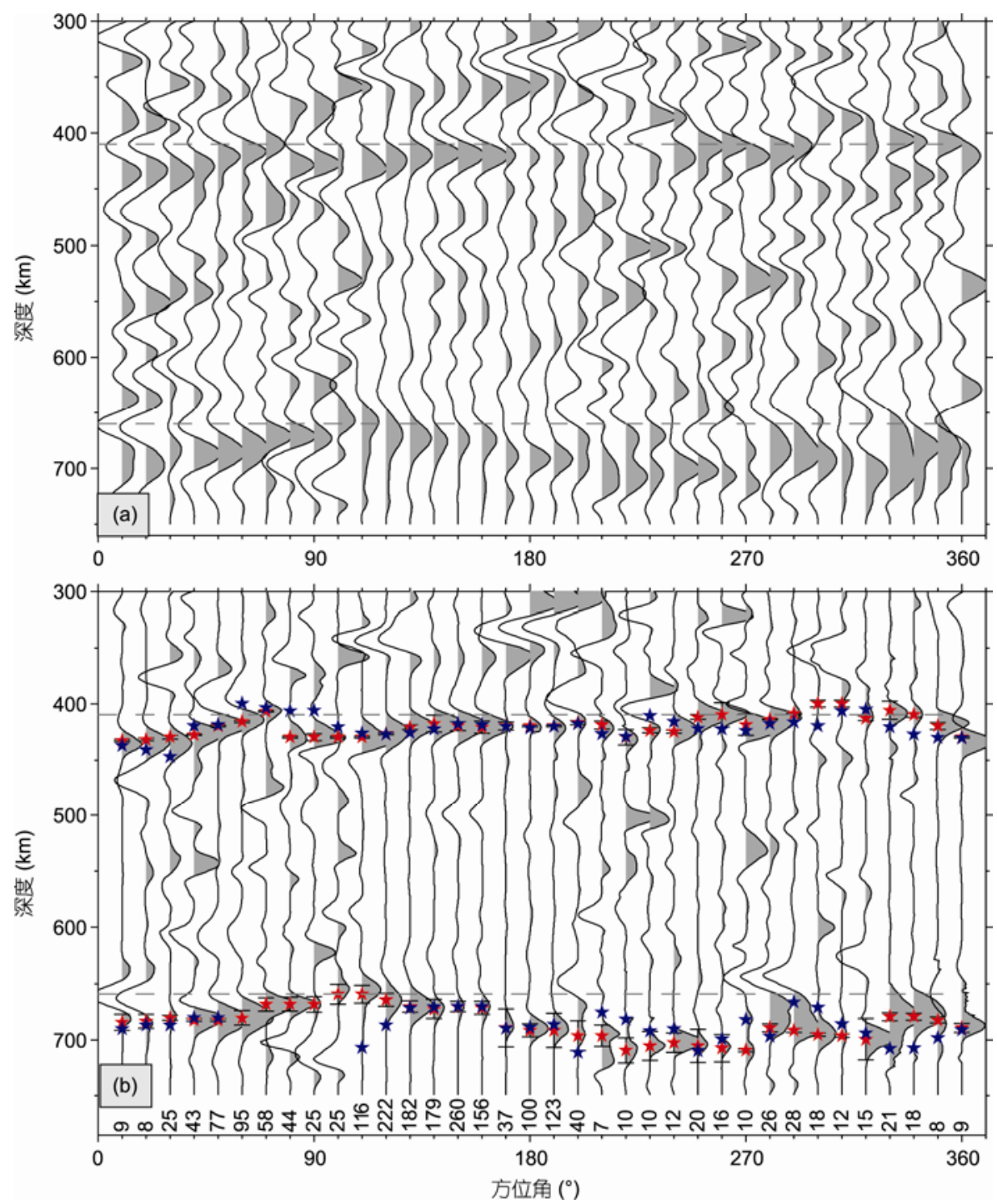

图 4 台站 TLY 径向接收函数分区域叠加的结果

(a)和(b)分别表示用线性叠加方法和相位加权叠加获得的结果. (b)中红色五角星为拾取的 $410 \mathrm{~km}$ 和 $660 \mathrm{~km}$ 间断面的深度, 并且通过 bootstrap 算法计算的均方差作为误差用误差棒标在此处; 蓝色五角星为 $\mathrm{Liu}$ 等 ${ }^{[55]}$ 的结果

\section{$2.1 .1410 \mathrm{~km}$ 间断面 $(\mathrm{d} 410)$}

从图 6(a)(红色星号)我们可以看出: $410 \mathrm{~km}$ 间断 面的深度最浅值为 $(400 \pm 3) \mathrm{km}\left(310^{\circ}, 320^{\circ}\right)$, 最深达到 $(433 \pm 1) \mathrm{km}\left(10^{\circ}, 360^{\circ}\right)$, 平均深度值为 $(419 \pm 2) \mathrm{km}$, 整 体上比正常值加深 $10 \mathrm{~km}$.

在台站反方位角 $0^{\circ} \sim 70^{\circ}$ 之间, $410 \mathrm{~km}$ 间断面从 大约 $430 \mathrm{~km}$ 逐渐变浅达到 $409 \mathrm{~km}$, 有一个明显的上 倾; $80^{\circ} \sim 110^{\circ}$ 之间, 间断面起伏不大, 平均深度值为 $430 \mathrm{~km}$, 比正常值加深 $20 \mathrm{~km}$; 在 $120^{\circ} \sim 240^{\circ}$ 之间, d410 的深度值起伏也不大, 表现的比较平, 基本上 与平均值一致; $250^{\circ} \sim 350^{\circ}$ 之间, $410 \mathrm{~km}$ 间断面普遍上 倾变浅, 在 $310^{\circ}$ 和 $320^{\circ}$ 处达到最浅 $400 \mathrm{~km}$.

\section{$2.1 .2660 \mathrm{~km}$ 间断面 $(\mathrm{d} 660)$}

在图 6(b)(红色星号)中, 我们可以得到：660 km 间断面平均深度值为 $(687 \pm 6) \mathrm{km}$, 相比于全球 $\mathrm{d} 660$ 深度值 ${ }^{[31]} 660 \mathrm{~km}$ 有明显的加深. 其最浅值在反方位 角 $100^{\circ}$ 和 $110^{\circ}$ 时达到 $(660 \pm 8) \mathrm{km}$; 最深值为 $(710 \pm 2)$ $\mathrm{km}$, 出现在其反方位角 $270^{\circ}$ 的位置. 

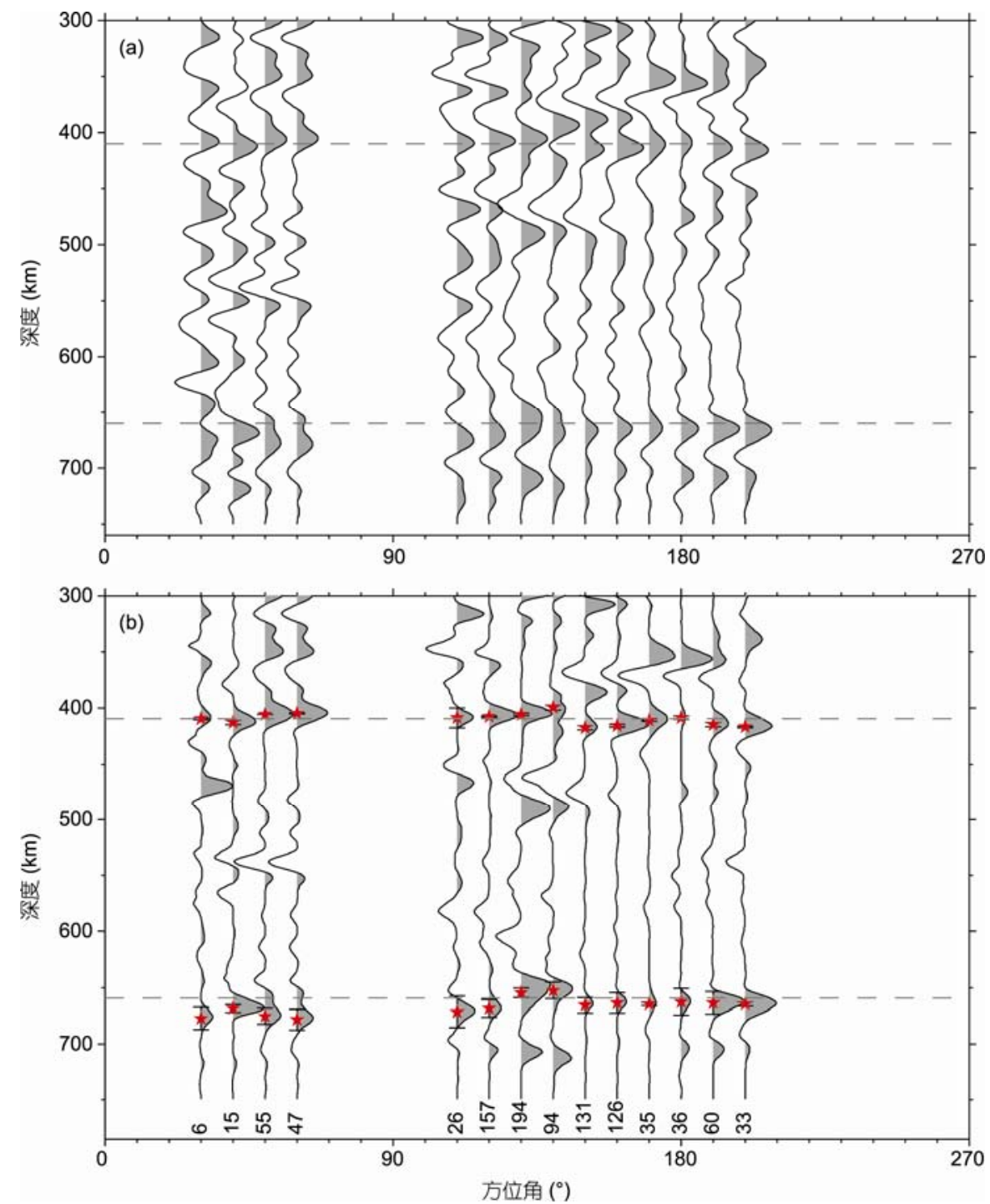

图 5 台站 ULN 径向接收函数分区域叠加的结果

(a)和(b)分别表示用线性叠加方法和相位加权叠加获得的结果. (b)中红色五角星为拾取的 $410 \mathrm{~km}$ 和 $660 \mathrm{~km}$ 间断面的深度, 并且通过 bootstrap 算法计算的均方差作为误差用误差棒标在此处

在台站反方位角 $330^{\circ} \sim 60^{\circ}$ 之间，间断面表现平 缓, 平均深度为 $683 \mathrm{~km}$; 而在 $70^{\circ} \sim 160^{\circ}$ 之间, 间断面 整体上明显变浅, 平均深度为 $667 \mathrm{~km}$; 从 $170^{\circ} \sim 320^{\circ}$, 间断面又开始变深, 虽有起伏, 但起伏不大, 平均深 度为 $697 \mathrm{~km}$.

从整体台站东西两部来看, $660 \mathrm{~km}$ 间断面表现 出明显的东西差异, 西部明显比东部加深, 西部 $\mathrm{d} 660$ 平均值为 $698 \mathrm{~km}$, 而东部 $\mathrm{d} 660$ 的平均值为 675 $\mathrm{km}$.

\subsection{3 过渡带厚度(MTZ)}

一般认为地幔过渡带的厚度为 $250 \mathrm{~km}$. 从整体 上看(图 6(c)(红色星号)), 在本研究区内地幔过渡带 平均厚度为 $(267 \pm 8) \mathrm{km}$, 整体显示增厚, 指示一冷的 过渡带; 且西部明显大于东部: 西部地幔过渡带厚度 变化不大, 平均值为 $(284 \pm 9) \mathrm{km}$, 比正常值增厚 34 $\mathrm{km}$; 东部地幔过渡带厚度有所起伏, 平均值为 $(251 \pm 6)$ $\mathrm{km}$, 基本与正常值一致. 而在局部 $\left(80^{\circ} \sim 120^{\circ}\right)$, 地幔 过渡带有明显的减薄, 平均值为 $235 \mathrm{~km}$, 相比于正 
表 1 台站 TLY d410 和 $\mathrm{d660}$ 深度以及地幔过渡带厚度 ${ }^{\text {a) }}$

\begin{tabular}{|c|c|c|c|c|c|c|c|}
\hline 方位角 $\left(^{\circ}\right)$ & $\mathrm{d} 410(\mathrm{~km})$ & $\sigma 410(\mathrm{~km})$ & $\mathrm{d} 660(\mathrm{~km})$ & $\sigma 660(\mathrm{~km})$ & $H(\mathrm{~km})$ & $\sigma H(\mathrm{~km})$ & $N$ \\
\hline $0 \sim 20$ & 433 & 0.91 & 685 & 7.24 & 252 & 7.46 & 9 \\
\hline $10 \sim 30$ & 432 & 1.21 & 684 & 6.15 & 252 & 3.12 & 8 \\
\hline $20 \sim 40$ & 430 & 1.44 & 681 & 2.01 & 251 & 2.47 & 25 \\
\hline $30 \sim 50$ & 428 & 0.44 & 683 & 1.14 & 255 & 1.23 & 43 \\
\hline $40 \sim 60$ & 420 & 0.74 & 683 & 1.26 & 263 & 1.46 & 77 \\
\hline $50 \sim 70$ & 416 & 0.78 & 681 & 6.49 & 265 & 6.52 & 95 \\
\hline $60 \sim 80$ & 407 & 0.41 & 669 & 5.92 & 262 & 5.93 & 58 \\
\hline 70 90 & 430 & 0.69 & 669 & 6.18 & 239 & 6.21 & 44 \\
\hline $80 \sim 100$ & 430 & 3.19 & 669 & 6.84 & 239 & 8.81 & 25 \\
\hline $90 \sim 110$ & 430 & 0.72 & 660 & 8.88 & 230 & 8.91 & 25 \\
\hline $100 \sim 120$ & 430 & 0.77 & 660 & 7.77 & 230 & 8.81 & 116 \\
\hline $110 \sim 130$ & 427 & 0.95 & 665 & 5.52 & 238 & 5.62 & 222 \\
\hline $120 \sim 140$ & 421 & 2.29 & 671 & 5.15 & 250 & 6.32 & 182 \\
\hline $130 \sim 150$ & 418 & 7.67 & 673 & 8.45 & 255 & 11.41 & 179 \\
\hline $140 \sim 160$ & 420 & 4.26 & 671 & 4.39 & 251 & 6.12 & 260 \\
\hline $150 \sim 170$ & 421 & 5.39 & 672 & 5.63 & 251 & 7.81 & 156 \\
\hline $160 \sim 180$ & 420 & 3.53 & 690 & 16.86 & 270 & 17.23 & 37 \\
\hline 170 190 & 420 & 0.93 & 692 & 5.72 & 272 & 5.82 & 100 \\
\hline $180 \sim 200$ & 420 & 0.64 & 692 & 15.27 & 272 & 15.28 & 123 \\
\hline $190 \sim 210$ & 417 & 1.98 & 697 & 13.47 & 280 & 13.61 & 40 \\
\hline $200 \sim 220$ & 419 & 3.58 & 697 & 9.53 & 278 & 12.83 & 7 \\
\hline $210 \sim 230$ & 430 & 6.95 & 710 & 10.95 & 280 & 13.98 & 10 \\
\hline $220 \sim 240$ & 424 & 2.14 & 706 & 12.94 & 282 & 18.07 & 10 \\
\hline $230 \sim 250$ & 425 & 1.54 & 703 & 8.62 & 278 & 8.76 & 12 \\
\hline $240 \sim 260$ & 412 & 2.26 & 706 & 14.81 & 289 & 14.97 & 20 \\
\hline $250 \sim 270$ & 410 & 10.81 & 708 & 12.03 & 292 & 16.15 & 16 \\
\hline $260 \sim 280$ & 419 & 9.57 & 710 & 1.31 & 291 & 9.66 & 10 \\
\hline $270 \sim 290$ & 414 & 0.58 & 690 & 3.64 & 276 & 3.68 & 26 \\
\hline $280 \sim 300$ & 409 & 0.85 & 692 & 1.93 & 283 & 2.11 & 28 \\
\hline $290 \sim 310$ & 400 & 3.06 & 696 & 1.41 & 290 & 3.37 & 18 \\
\hline $300 \sim 320$ & 400 & 3.21 & 697 & 1.31 & 292 & 3.47 & 12 \\
\hline $310 \sim 330$ & 413 & 1.82 & 700 & 6.22 & 287 & 7.31 & 15 \\
\hline $320 \sim 340$ & 406 & 7.95 & 680 & 3.79 & 274 & 8.81 & 21 \\
\hline $330 \sim 350$ & 410 & 2.19 & 680 & 3.12 & 270 & 3.82 & 18 \\
\hline $340 \sim 360$ & 420 & 3.26 & 683 & 2.15 & 263 & 3.04 & 8 \\
\hline $350 \sim 10$ & 430 & 0.84 & 690 & 4.16 & 260 & 4.53 & 9 \\
\hline
\end{tabular}

a) d410 和 $\mathrm{d} 660$ 分别表示 $410 \mathrm{~km}$ 和 $660 \mathrm{~km}$ 间断面的深度; $\sigma 410$ 和 $\sigma 660$ 分别表示 $\mathrm{d} 410$ 和 $\mathrm{d} 660$ 的误差; $H$ 表示地幔过渡带的厚度; $\sigma H$ 表示地幔过渡带厚度误差; $N$ 为在叠加区间内接收函数的数目

常值减薄 $15 \mathrm{~km}$.

\section{2 台站 ULN}

从图 1 可以看出, ULN 台站的远震地震数据明显 少于 TLY, 且主要集中在台站的东南方, 在图 5 和表 2 中, 我们只展示了接收函数叠加数目 $\geqslant 6$ 、叠加震相 清晰的叠加结果.

\subsection{1 $410 \mathrm{~km}$ 间断面 (d410)}

如图 7(a)所示, 在我们获得叠加结果的地区 $\mathrm{d} 410$ 平均值为 $(410 \pm 2) \mathrm{km}$, 整体上起伏不大, 基本表 现为正常. $\mathrm{d} 410$ 在 $120^{\circ} \sim 140^{\circ}$ 之间有所上倾, 在 $140^{\circ}$ 达到最浅为 $(400 \pm 2) \mathrm{km}$.

\subsubsection{0 km 间断面 $(\mathrm{d} 660)$}

如图 7(b)所示, d660 平均值为 $(667 \pm 7) \mathrm{km}$, 整体 上没有大的起伏. 在 $30^{\circ} \sim 60^{\circ}$ 之间, d660 有所变深, 平 均为 $(675 \pm 6) \mathrm{km}$; 从 $110^{\circ} \sim 140^{\circ}, \mathrm{d} 660$ 有一个上倾, 在 $140^{\circ}$ 处达到最浅 $(640 \pm 7) \mathrm{km}$; 在 $150^{\circ} \sim 200^{\circ}$ 之间, d660 表现平缓, 平均为 $(664 \pm 8) \mathrm{km}$. 
司少坤等: 贝加尔裂谷区地幔过渡带大范围增厚与局部减薄现象及其动力学意义
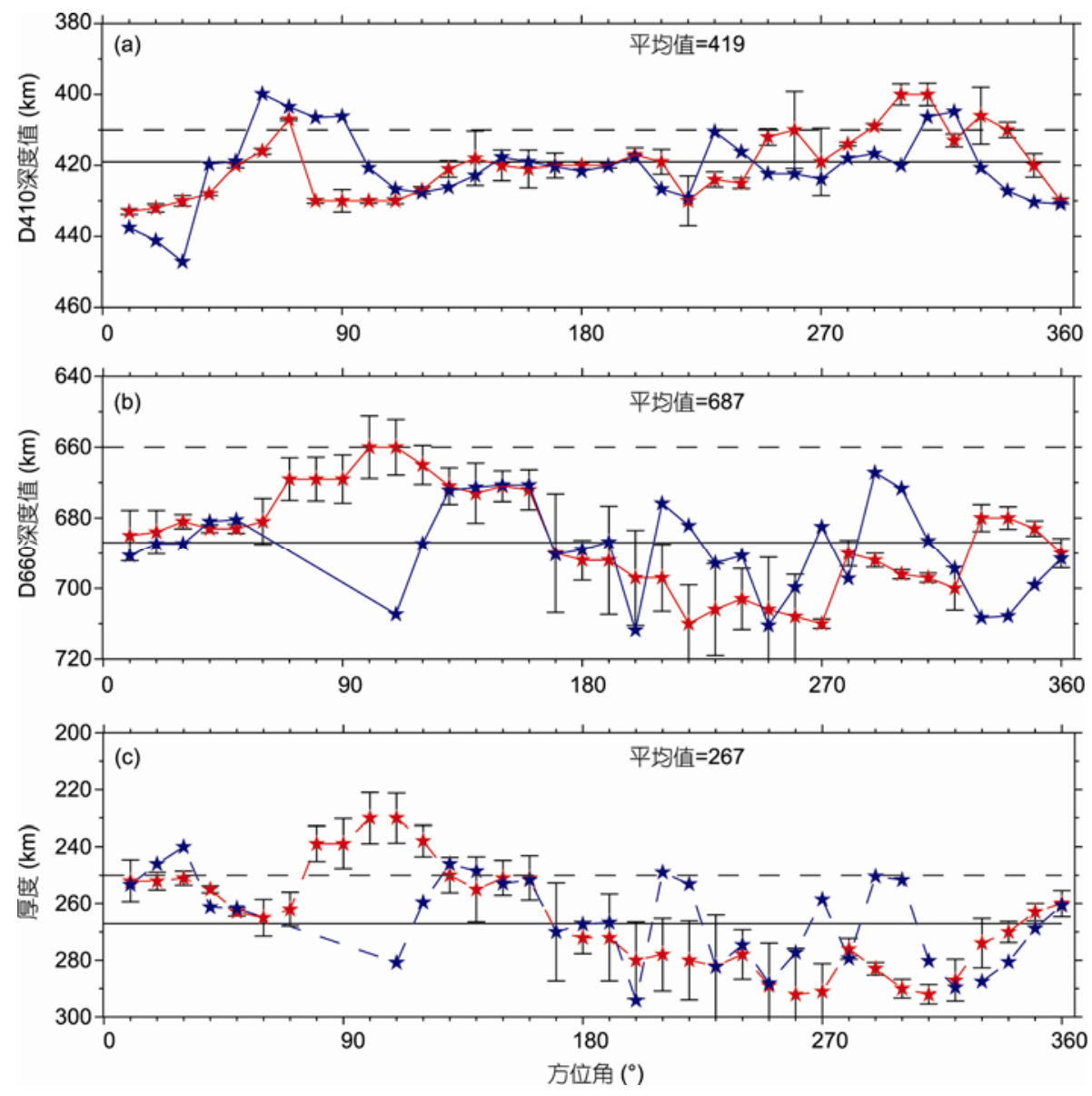

图 6 台站 TLY 获得的 $410 \mathrm{~km}$ 间断面(a)、660 $\mathrm{km}$ 间断面(b)和地幔过渡带厚度(c)的结果

红色五角星表示每个叠加区间内的间断面和地幔过渡带厚度值, 两侧短横棒为误差棒, 蓝色五角星为 Liu 等 ${ }^{[55}$ 的结果. 虚线为正常的间断面 和过渡带厚度值, 实线为 TLY 下方间断面和过渡带厚度的平均值

表 2 台站 ULN d410 和 $\mathbf{d 6 6 0}$ 深度值以及地幔过渡带厚度

\begin{tabular}{|c|c|c|c|c|c|c|c|}
\hline 方位角 $\left(^{\circ}\right)$ & $\mathrm{d} 410(\mathrm{~km})$ & $\sigma 410(\mathrm{~km})$ & $\mathrm{d} 660(\mathrm{~km})$ & $\sigma 660(\mathrm{~km})$ & $H(\mathrm{~km})$ & $\sigma H(\mathrm{~km})$ & $N$ \\
\hline $20 \sim 40$ & 410 & 0.81 & 678 & 9.36 & 268 & 9.39 & 6 \\
\hline $30 \sim 50$ & 413 & 1.99 & 669 & 3.09 & 256 & 3.68 & 15 \\
\hline $40 \sim 60$ & 406 & 0.11 & 676 & 7.22 & 270 & 7.22 & 55 \\
\hline $50 \sim 70$ & 405 & 0.51 & 679 & 9.35 & 274 & 9.36 & 47 \\
\hline $100 \sim 120$ & 409 & 8.89 & 672 & 10.72 & 263 & 13.93 & 26 \\
\hline $110 \sim 130$ & 408 & 0.53 & 669 & 7.79 & 261 & 7.8 & 157 \\
\hline $120 \sim 140$ & 406 & 0.78 & 655 & 4.39 & 249 & 4.41 & 194 \\
\hline $130 \sim 150$ & 400 & 1.93 & 653 & 7.09 & 253 & 7.34 & 94 \\
\hline $140 \sim 160$ & 418 & 1.84 & 666 & 6.7 & 248 & 6.94 & 131 \\
\hline $150 \sim 170$ & 416 & 1.23 & 664 & 9.06 & 248 & 9.14 & 126 \\
\hline $160 \sim 180$ & 411 & 1.27 & 665 & 0.87 & 254 & 1.29 & 35 \\
\hline $170 \sim 190$ & 409 & 1.41 & 663 & 11.7 & 254 & 11.78 & 36 \\
\hline 180 200 & 415 & 1.91 & 664 & 9.7 & 249 & 9.88 & 60 \\
\hline $190 \sim 210$ & 417 & 0.67 & 665 & 0.86 & 248 & 2.09 & 33 \\
\hline
\end{tabular}



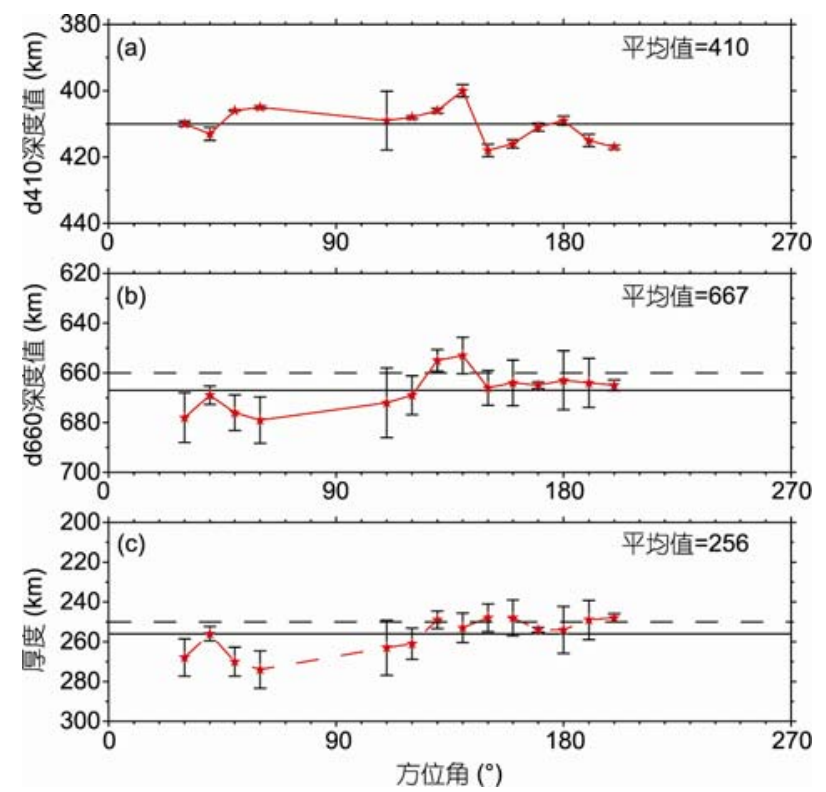

图 7 台站 ULN 获得的 $410 \mathrm{~km}$ 间断面(a)、660 $\mathrm{km}$ 间断面 (b) 和地幔过渡带厚度(c)的结果

红色五角星表示每个叠加区间内的间断面和地幔过渡带厚度值, 两 侧的短黑线为误差棒. 虚线为正常的间断面和过渡带厚度值, 实线 为 ULN 下方间断面和过渡带厚度的平均值

\subsection{3 过渡带厚度(MTZ)}

从图 7(c)中我们可以看出, 在此区域地幔过渡带 的厚度平均为 $(256 \pm 7) \mathrm{km}$. 在 $30^{\circ} \sim 60^{\circ}$ 之间, 地幔过 渡带有所增厚, 平均为 $(270 \pm 6) \mathrm{km}$, 从 $110^{\circ}$ 开始, 地 幔过渡带开始趋于正常, 在 $110^{\circ} \sim 200^{\circ}$ 之间, 地幔过 渡带厚度基本为 $(250 \pm 7) \mathrm{km}$.

\section{3 讨论}

\section{1 误差分析}

由于我们在计算接收函数转换点时和走时时, 使用的是 IASP91 标准地球模型 ${ }^{[45]}$, 而实际在该区域 地壳上地幔的地震波速度是横向非均匀和各向异性 的. 前人的研究 ${ }^{[14,37]}$ 表明在贝加尔裂谷下方的上地 幔中存在着低速层, 因此我们所得到的 $\mathrm{d} 410$ 和 $d 660$ 的深度值就会比实际值偏大，偏离幅度可达 10 20 $\mathrm{km}$; 另外, 地震波速度的方位各向异性亦会影响 $\mathrm{d} 410$ 和 $\mathrm{d} 660$ 的深度值的测量. 在本研究区剪切波分 裂研究表明 ${ }^{[20,56 ~ 59]}$, 贝加尔地区方位各向异性特征 较为复杂: 西伯利亚地台和贝加尔湖下方快波方向 为约为 $63^{\circ}$, 时差为 $1.27 \mathrm{~s}$; 蒙古高原下方约为 $120^{\circ}$,
时差约为 $1.1 \mathrm{~s}$. 因此, 可能导致 TLY 台站下方 $60^{\circ}$ 左 右 $\mathrm{d} 410$ 和 $\mathrm{d} 660$ 的深度值变小(图 6(a)和(b)); 而其他 方位由于上地幔低速的影响, 方位各向异性的影响特 征不明显. 但是以上因素对地幔过渡带厚度的影响不 大, 因为其对射线 P410s 和 P660s 的影响是一样的.

另外, 地幔过渡带内介质横向不均匀性对我们 的结果也会造成影响. 假设在地幔过渡带的速度模 型中引入一 $2 \%$ 的高速异常区, 会使 $\mathrm{d} 660$ 值增加大约 $5 \mathrm{~km}$. 同样, 以上两种情况相对于我们所得到异常幅 度小很多, 不影响总体的分析.

\section{2 结果分析}

对于台站 TLY, 虽然我们的数据量相对于此地 区以前 $\mathrm{Liu}$ 和 $\mathrm{Gao}^{[55]}$ 的研究(1718 条接收函数)有所减 少, 但我们也获得了更清晰地叠加震相(图 4). 与其 结果相比, 我们在反方位角 $60^{\circ} \sim 100^{\circ}$ 之间的 $660 \mathrm{~km}$ 间断面也得到了比较可靠的震相. 在图 6 中我们分别 标出了我们(红色星号)和 $\operatorname{Liu}$ (蓝色星号)的结果, 从图 6 看, 我们的结果整体上与其相一致, 例如: 我们在 研究区获得的 $410 \mathrm{~km}$ 与 $660 \mathrm{~km}$ 间断面和地幔过渡带 厚度平均值分别是 419,687 和 $267 \mathrm{~km}$, 与其 421,688 和 $265 \mathrm{~km}$ 基本一致; 大部分叠加区间的深度值也相一 致, $410 \mathrm{~km}$ 间断面尤为明显. 但在局部地区也有所差 异, Liu 的 $410 \mathrm{~km}$ 间断面在 $30^{\circ} \sim 100^{\circ}$ 均表现为上倾 ${ }^{[5]}$, 而我们的结果显示, 在 $30^{\circ} \sim 70^{\circ}$ 表现为上倾, $70^{\circ}$ 处达 到最浅, 而从 $80^{\circ}$ 开始变深; 另外, Liu 的 $660 \mathrm{~km}$ 间断 面在 $60^{\circ} \sim 100^{\circ}$ 没有得到结果, 根据 $410 \mathrm{~km}$ 间断面的 结果推测 $660 \mathrm{~km}$ 间断面, 从而得出在此地区地幔过 渡带增厚, 而我们在此区域得到了比较明显的 660 $\mathrm{km}$ 间断面的震相, 且得出在此地区地幔过渡带减薄 的结果.

从我们得到的结果看(图 8(a), (b)), TLY 下方 $\mathrm{d} 410$ 和 d660 都有明显的变深, 而 ULN 处的 d410 和 d660 基本表现为正常, 我们认为这可能是在 TLY 下方的 上地幔中存在低速层所导致的, 这与最近层析成像 的结果一致 ${ }^{[14,36]}$. 从整体上看(图 8(c)), 地幔过渡带 厚度在蒙古南部显示为正常, 向北有逐渐增厚的趋 势, 在贝加尔裂谷地区及西伯利亚高原南部绝大部 分呈显著增厚, 仅有一小范围的、小幅度的减薄在台 站 TLY 反方位角 $80^{\circ} \sim 120^{\circ}$ 内. 对于裂谷下方 $\left(80^{\circ} \sim\right.$ $\left.120^{\circ}, \mathrm{TLY}\right)$ 的小范围减薄, 我们认为在此处可能有一 热物质上涌引起地幔过渡带温度升高, 然而其规模 

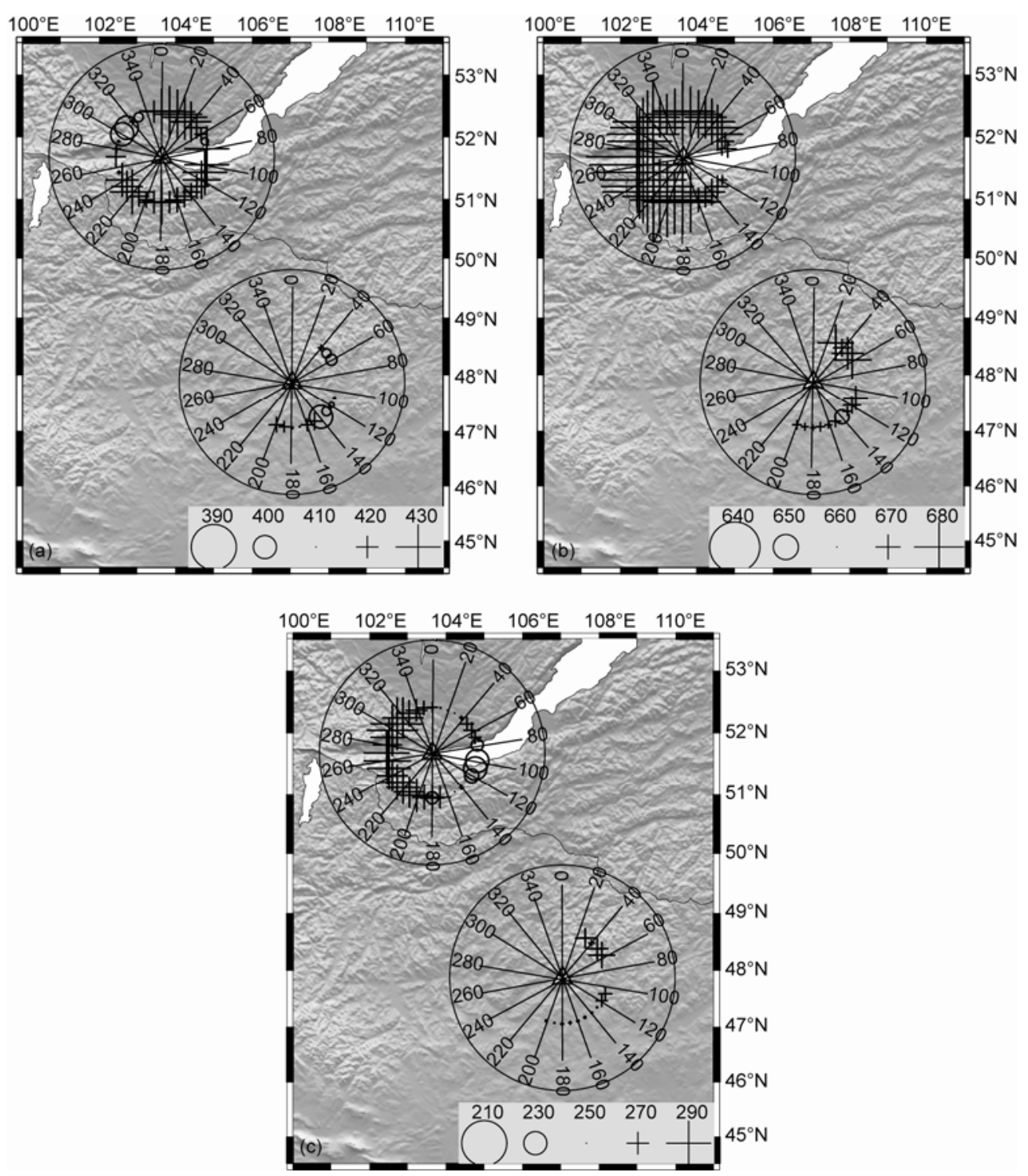

图 $8 \mathrm{d410(a),d660(b)}$ 间断面深度和 MTZ(c)厚度分布

十字和圆圈分别表示相对于正常值变深(增厚)和变浅(减薄)

相对较小, 不可能是诱发贝加尔裂谷发育的主导因 素, 但其对裂谷的形成有着一定的贡献, 如对西伯利 亚板块与贝加尔禩皱带之间的缝合带产生热弱化作 用，从而有利于裂谷的形成与发育. Lobatskaya ${ }^{[60]}$ 以 及 Mats 等 ${ }^{[61]}$ 的研究指出, 在空间上贝加尔裂谷由东 北向西南方向发育, 若地幔柱是其演化发育的主因, 其必存在于台站 TLY 的东侧或东北侧, 这与我们得 到的结果基本一致. Mats 和 Perepelova ${ }^{[62]}$ 最近的研究 认为, 现阶段裂谷的发育主要受热地幔物质上涌控 制, 可以推测贝加尔裂谷将会继续向西南方向发育,
从属于递进的沉降和加宽直至最终发育为盆地. 对 于裂谷地区以及西伯利亚高原南部绝大部分地幔过 渡带增厚, 我们认为有两种可能: 其一, 在中生代期 由于蒙古-鄂霍次克板片向西北不断地俯冲 ${ }^{[63]}$, 导致 蒙古-华北板块与西伯利亚高原发生碰撞, 使地壳和 岩石圈增厚, 并在下地壳产生榴辉岩化, 由于重力不 稳, 发生拆沉作用, 拆沉的块体下落到地幔过渡带内, 并保留下来, 使地幔过渡带内温度下降, 从而造成地 幔过渡带增厚; 其二, 在裂谷发育过程中引起小规模 的地幔物质上涌，侵入下地壳内，同样产生重力不稳， 
发生拆沉作用, 拆离部分进入地幔过渡带内, 造成地 幔过渡带增厚. 拆沉作用诱发软流圈物质上涌, 使岩 石圈减薄弱化, 并且拆离落入过渡带内的板片所含 的大量水分进入上地幔, 降低了上地幔物质熔点, 使 其熔融程度增高, 从而加速了地幔对流 ${ }^{[64]}$, 地幔对流 的热作用和裂谷区的应力积累使岩石层强度降低, 随着印度板块与欧亚板块的碰撞, 处于印度板块与 西伯利亚高原之间的亚洲大陆构造块体向东被挤出, 贝加尔地区在印度板块北进和北美板块相对于欧亚 大陆逆时针旋转的双重挤压下发生东西扩展拉张, 逐渐形成裂谷 ${ }^{[65]}$.

\section{4 结论}

我们利用研究区内两个台站的大量接收函数数
据(1847 条)对研究区进行研究, 得到了研究区内 410 $\mathrm{km}$ 和 $660 \mathrm{~km}$ 间断面的深度值以及地幔过渡带的厚 度: 在贝加尔裂谷下方的 $\mathrm{d} 410$ 和 $\mathrm{d} 660$ 值偏大, 而且 地幔过渡带整体上增厚，仅在台站反方位角 $80^{\circ}$ $120^{\circ}$ 之间, 地幔过渡带有小幅度的减薄. 我们认为在 贝加尔裂谷地区上地幔广泛分布有低速区，导致转 换波走时增加, 从而使接收函数中 $\mathrm{d} 410$ 和 $\mathrm{d} 660$ 值偏 大; 引起地幔过渡带增厚的原因可能有二: 其一, 由 于在中生代蒙古-华北板块 (Mongolia-North China Continent)与西伯利亚板块发生碰撞, 地壳和岩石圈 增厚, 并发生榴辉岩化导致拆沉, 拆离部分在地幔过 渡带内滞留, 产生地幔过渡带变厚结果. 另一可能为 有一小规模的地幔物质上涌侵入下地壳, 导致重力 不稳, 而发生拆沉. 这种拆沉作用对裂谷的发育有重 要的影响.

\section{参考文献}

1 杨巍然, 纪克诚, 孙继源, 等. 大陆裂谷研究中的几个前沿课题. 地学前缘, 1995, 2: 93-102

2 Milanovsky E E. Continental rift zone: Their arrangement and development. Tectonophysics, 1972, 15: 65-70

3 Zonenshain L P, Savostin L A. Geodynamics of the Baikal rift zone and plate tectonics of Asia. Tectonophysics, 1981, 76: 1-45

4 Illies J. An intercontinental belt of the world rift system. Tectonophysics, 1969, 8: 5-29

5 Sengor A M, Burke K. Relative timing of rifting and volcanism on Earth and its tectonic implications. Geophys Res Lett, 1978, 5: 419-421

6 Doser D. Faulting within the western Baikal rift as characterized by earthquake studies. Tectonophysics, 1991, 196: 87-107

7 Keller G R, Bott M H, Wendlandt R F, et al. The Baikal rift system. In: Olsen K H, ed. Continental Rifts: Evolution, Structure, Tectonics. New York: Elsevier Science, 1995. 325-344

8 Zorin Y A, Cordell L. Crustal extension in the Baikal rift zone. Tectonophysics, 1991, 198: 117-121

9 Calais E, Lesne O, Deverchere J, et al. Crustal deformation in the Baikal rift from GPS measurements. Geophys Res Lett, 1998, 25: 4003-4006

10 Suvorov V D, Mishenkina Z M, Petrick G V, et al. Structure of the crust in the Baikal rift zone and adjacent areas from deep seismic sounding data. Tectonophysics, 2002, 351: 61-74

11 Lysak S V. Terrestrial heat flows of continental rifts. Tectonophysics, 1984, 103: 205-215

12 Zorin Y A, Kozhevnikov V M, Novoselova M R, et al. Thickness of the lithosphere beneath the Baikal rift zone and adjacent regions. Tectonophysics, 1989, 168: 327-337

13 Gao S, Liu K, Davis P, et al. Evidence for small-scale mantle convection in the upper mantle beneath the Baikal rift zone. J Geophys Res, 2003, 108: 2194

14 Kiselev A. Volcanism of the Baikal rift zone. Tectonophysics, 1987, 143: 235-244

15 Achauer U, Masson F. Seismic tomography of continental rifts revisited: From relative to absolute heterogeneities. Tectonophysics, 2002, 358: $17-37$

16 Gao S, Liu K, Chen C. Significant crustal thinning beneath the Baikal rift zone: New constraints from receiver functions analysis. Geophys Res Lett, 2004, 31: L20610

17 Nielsen C, Thybo H. No Moho uplift below the Baikal Rift Zone: Evidence from a seismic refraction profile across southern Lake Baikal. J Geophys Res, 2009, 114: B08306

18 Logatchev N A, Zorin Y A. Baikal rift zone: Structure and geodynamics. Tectonophysics, 1992, 208: 273-286

19 Egorkin A V, Ziuganov R D, Chernyshev N M. The upper mantle of Siberia. Proc Int Geol Congr, 1984, 27: 26-29

20 Gao S, Davis P M, Liu H, et al. SKS splitting beneath continental rift zones. J Geophys Res, 1997, 102: 22781-22797

21 Logatchev N, Florensov N. The Baikal system of rift valleys. Tectonophysics, 1978, 45: 1-13 
22 Artyushkov E, Letnikov F A, Ruzhich F A, et al. The mechanisms of formation of the Baikal Basin. J Geodyn, 1990, 11: 277-291

23 Zorin Y A. The Baikal rift: An example of the intrusion of asthenospheric material into the lithosphere as the cause of disruption of lithospheric plates. Tectonophysics, 1981, 73: 91-104

24 Zorin Y A. Geodynamics of the western part of the Mongolia-Okhotsk collisional belt, Trans-Baikal region and Mongolia. Tectonophysics, 1999, 306: 33-56

25 Koulakov I. Role of the plume in development of the Baikal rift (from teleseimic and local tomography). In: Achauer U, ed. ILP-workshop on "Plume-Lithosphere Interactions Strasbourg". 9-11 April, 2000. 63-65

26 Logatchev N A, Zorin Y A. Baikal rift: Active or passive?-Comparison of the Baikal and Kenya rift zones. Tectonophysics, 1983, 94: 223-240

27 Molnar P, Tapponnier P. Cenozoic tectonics of Asia: Effects of a continental collision. Science, 1975, 189: 419-426

28 Zoenshain L P, Savostin L. Geodynamics of the Baikal rift zone and plate tectonics of Asia. Tectonophysics, 1981, 76: 1-45

29 Kiselev A I, Popov A M. Asthenospheric diaper beneath the Baikal rift: Petrologic constraints. Tectonophysics, 1992, 208: 287-295

30 Achauer U, Masson F. Seismic tomography of continental rifts revisited: From relative to absolute heterogeneities. Tectonophysics, 2002, 358: $17-37$

31 Yin A. Mode of Cenozoic east-west extension in Tibet suggesting a common origin of rifts in Asia during the Indo-Asian collision. J Geophys Res, 2000, 105: 21745-21760

32 Petit C, Deverchere J, Sankov F. Present-day stress field changes along the Baikal rift and tectonic implications. Tectonics, 1996, 15: $1171-1191$

33 Delvaux D, Moeys R, Stapel G, et al. Paleostress reconstructions and geodynamics of the Baikal region, central Asia. Tectonophysics, 1997, 282: $1-38$

34 Lesne O, Calais E, Deverchere J, et al. Dynamics of intracontinental extension in the north Baikal rift from two-dimensional numerical deformation modeling. J Geophys Res, 2000, 105: 21727-21744

35 杨巍然, 隋志龙, Mast V D. 俄罗斯贝加尔湖区伸展构造及与中国东部伸展构造对比. 地球科学进展, 2003, 18: 45-49

36 Zhao D P, Lei J, Inoue A, et al. Deep structure and origin of the Baikal rift zone. Earth Planet Sci Lett, 2006, 243: 681-691

37 Gao S, Davis P M, Liu H, et al. Asymmetric upwarp of the asthenosphere beneath the Baikal rift zone, Siberia. J Geophys Res, 1994, 99: $15319-15330$

38 Malamud B D, Turcotte D L. How many plumes are there? Earth Planet Sci Lett, 1999, 174: 113-124

39 Zorin Y A, Turutanov E K, Mordvinova V, et al. The Baikal rift zone: The effect of mantle plumes on older structure. Tectonophysics, 2003, 371: 153-173

40 Petit C, Koulakov I, Deverchere J. Velocity structure around the Baikal rift zone from teleseismic and local earthquake traveltimes and geodynamic implications. Tectonophysics, 1998, 296: 125-144

41 Bina C R, Helffrich G. Phase transition Clapeyron slopes and transition zone seismic discontinuity topography. J Geophys Res, 1994, 99: 15853-15860

42 刘启元, 李顺成, 沈杨, 等. 延怀盆地及其邻区地壳上地幔速度结构的宽频带地震台站研究. 地球物理学报, 1997, 40: 763-771

43 吴庆举, 曾融生. 用宽频带远震接收函数研究青藏高原的地壳结构. 地球物理学报, 1998, 41: 669-679

44 胡家富, 苏有锦, 朱雄关, 等. 云南的地壳 S 波速度与泊松比结构及其意义. 中国科学 D 辑: 地球科学, 2003, 33: 714-722

45 Kennett B L, Engdahl E R. Traveltimes for global earthquake location and phase identification. J Geophys Res, 1991, 105: 429-465

46 Ai Y, Zheng T. The upper mantle discontinuity structure beneath eastern China. Geophys Res Lett, 2003, 30: 2089, doi: 10.1029/ 2003GL017678

47 Chen L, Ai Y. Discontinuity structure of the mantle transition zone beneath the North China Craton from receiver function migration. J Geophys Res, 2009, 114: B06307, doi: 10.1029/2008JB006221

48 沈旭章, 周蕙兰. 接收函数 CCP-PWS 偏移方法探测中国东北地区 $620 \mathrm{~km}$ 深处低速层. 科学通报, 2009, 54: 215-223

49 Zhang Z, Yuan X, Chen Y, et al. Seismic signature of the collision between the east Tibetan escape flow and the Sichuan Basin. Earth Planet Sci Lett, 2010, doi: 10.1061/j.espl.2010.01.046

50 Tian X, Zhao D, Zhang H, et al. Mantle transition zone topography and structure beneath the central Tien Shan orogenic belt. J Geophys Res, 2010, 115: B10308, doi: 10.1029/2008JB006229

51 Langston C A. Structure under Mount Rainer, Washington, inferred from trleseismic body waves. J Geophys Res, 1979, 84: 4794-4762

52 Schimmel M, Paulssen H. Noise reduction and detection of weak, coherent signals through phase-weighted stacks. J Geophys Res, 1997, 130: 497-505 
53 Press W H, Teukolsky S A, Vetterling W T, et al. Numerical Recipes in FORTRAN. 2nd ed. New York: Cambridge Univ. Press, 1992

54 Efron B, Tibshirani R. Bootstrap methods for standard errors, confidence intervals, and other measures of statistical accuracy. Stat Sci, 1986, 1: $54-75$

55 Liu K, Gao S. Mantle transition zone discontinuities beneath the Baikal rift and adjacent areas. J Geophys Res, 2006, 111: B11301

56 罗艳, 黄忠贤, 彭艳菊, 等. 中国大陆及邻区 SKS 波分裂研究. 地球物理学报, 2004, 47: 812-821

57 Barruol G, Deschamps A, Deverchere J, et al. Upper mantle flow beneath and around the Hangay dome, Central Mongolia. Barth Planet Sci Lett, 2008, 274: 221-233

58 Liu K H, Gao S S, Gao Y, et al. Shear wave splitting and mantle flow associated with the deflected Pacific slab beneath northeast Asia. J Geophys Res, 2008, 113: B01305, doi: 10.1029/2007JB005178

59 张建利, 田小波, 张中杰, 等. 贝加尔裂谷地区地壳上地幔各向异性研究. 地球物理学报, 2012, doi: 10.6038/j.issn.001-5733.2012.08.005

60 Lobatskaya R M. Neotectonic fault-block structure of junction of Siberian platform and west Siberian plate. Russ Geo Geophys, 2005, 46: 141-150

61 Mats V, Lobatskaya R, Khlystov O. Evolution of faults in a continental rift: Morphotectonic evidence from the southwestern termination of the north Baikal basin. Earth Sci Fron, 2007, 14: 207-219

62 Mats A D, Perepelova T I. A new perspective on evolution of the Baikal Rift. Geosci Fron, 2011, 2: 349-365

63 Meng Q. What drove late Mesozoic extension of the northern China-Mongolia tract? Tectonophysics, 2003, 369: 155-174

64 Kelbert A, Schultz A, Egbert G. Global electromagnetic induction constraints on transition-zone water content variations. Nature, 2009, 460: 1003-1007, doi: 10.1038/nature08257

65 熊熊, 单斌, 王继业, 等. 蒙古-贝加尔地区上地幔小尺度对流及地球动力学意义. 地球物理学报, 2010, 53: 1594-1604, doi: 10.3969/j.issn.0001-5733.2010.07.010 